\title{
Evaluating research recruitment strategies to improve response rates amongst South African nurses
}

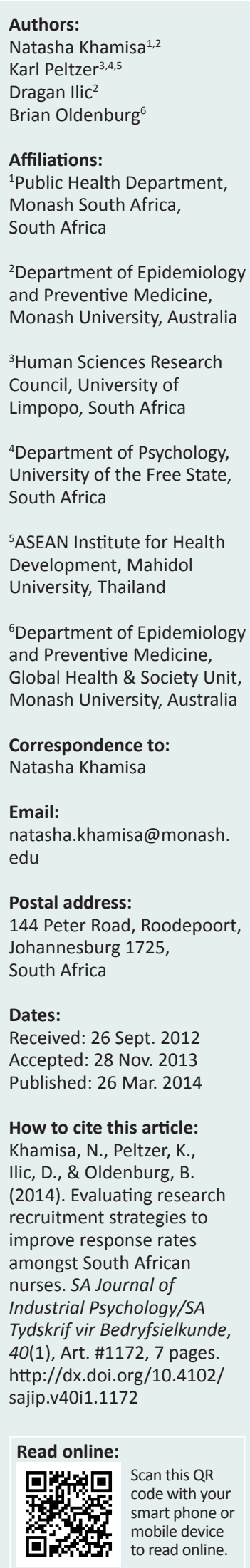

Orientation: Nurse recruitment to and participation in empirical research is increasingly important in understanding and improving nursing practice. However, the low participation and recruitment rate amongst nurses is not well understood.

Research purpose: The aim of this study was to evaluate three research recruitment methods for their impact on recruitment and participation rates amongst South African nurses.

Motivation for the study: A limited number of studies exist that formally evaluates different recruitment strategies to improve participation in research amongst nurses within developing contexts, especially South Africa.

Research approach, design and method: Participants were recruited using three different methods. Of the 250 nurses randomly selected and invited to participate in a cross-sectional survey, 201 agreed and 162 (81\%) returned the questionnaires.

Main findings: Nursing management participation in the recruitment and data collection process produces more favourable response rates. Reminders and the use of shorter questionnaires also aid higher response rates.

Practical/managerial implications: Reminders as well as face-to-face recruitment strategies (especially by a familiar person) successfully improved participation rates amongst South African nurses in this study.

Contribution/value-add: This study identifies some strategies that could be used more widely to increase the recruitment and participation of South African nurses in research whilst potentially improving their work situation.

\section{Introduction}

\section{Key focus}

Nurse recruitment for participation in empirical research is gradually becoming more important in developing evidence-based strategies to improve nursing practice (Fineout-Overholt, Levin \& Melnyk, 2004). This is achievable through high response rates, which determine the generalisability of findings and therefore the success or failure of a research study (Burns \& Grove, 2007). Despite this, limited research has focused on how to improve the recruitment and participation of nurses in such research (Webb, 2002). This is evident in a recent systematic review conducted by Edwards et al. (2009), who found only a handful of outdated studies that focused on methods of recruiting nurses for participation in research.

\section{Background}

Studies with nurses as participants often report lower response rates (below 60\%) compared to studies with other health professionals, such as physicians, pharmacists, dentists, occupational therapists, physiotherapists and radiographers (Hill, Fahrney, Wheeless \& Carson, 2006; Ulrich \& Grady, 2004). In comparison, studies on a variety of health topics amongst doctors typically report response rates of above 60\% (Cook, Dickinson \& Eccles, 2009).

\section{Literature review}

Various factors, such as disinterest in the research topics, highly sensitive questionnaires, no specification of deadlines for return of questionnaires as well as no assurance of confidentiality, have generally been reported to influence research participation rates (Edwards et al., 2009). However, there are some more specific individual and organisation-level barriers that affect participation by nurses in different kinds of research studies (Chan et al., 2011). At the individual 
level, nurses' knowledge of and attitudes towards research influence response rates. Poor perceptions of the study may deter nurses from participating, since they may not appreciate and understand the value and applicability of the study within the broader healthcare context (Broyles, Rodriguez, Price, Bayliss \& Sevick, 2011; Hummers-Pradier et al., 2008). Providing detailed written or verbal information to participants about the research aims and study context has been demonstrated to increase response rates above $70 \%$ (Broyles et al., 2011; Hill et al., 2006; Madu \& Mamomane, 2003; Thorsen, Tharp \& Meguid, 2011; Van der Doef, Mbazzi \& Verhoeven, 2012).

The primary organisation-level barrier affecting nurse participation rates is a lack of involvement by stakeholders in the recruitment and research process. The negative influence of this barrier could be reduced by involving nursing managers and supervisors in the recruitment and questionnaire distribution process. Previous research has demonstrated that this participation increases response rates by more than 40\% (Broyles et al., 2011; Choi, Pak \& Purdham 1990). Overcoming logistical barriers relating to the recruitment and research site can also increase response rates with on-site recruitment of participants eliciting high response rates of above $70 \%$ (Broyles et al., 2011).

Other barriers that may affect response rates in nursing studies include confidentiality issues regarding responses provided (Jacobson, Warner, Fleming \& Schmidt, 2008; Purkis, Jackson, Hundt \& Stockman, 2008), length of questionnaires (Edwards et al., 2009) and the complex nature of nursing tasks (Corcoran, 2007; Cummins, 2006; Weierbech, Glick, Fletcher, Rowlands \& Lyder, 2010). In addressing these barriers, strategies such as reassuring participants of confidentiality, using shorter questionnaires, as well as extending deadlines and issuing reminders have improved response rates (Edwards et al., 2009).

The success of different individual and organisation-level strategies in improving response rates might also depend on the context and they may not necessarily be generalised across populations, settings and countries (Gore-Felton, Koopman, Bridges, Thoresen \& Spiegel, 2002; Hill et al., 2006). In particular, strategies that have been shown to improve participation of nurses in research studies performed in developed countries may not be as effective within the same population in developing countries. For example, providing a cover letter to potential nurse participants has been shown to be a successful strategy in an American study (response rate 72\%) (Hill et al., 2006); however, the same strategy employed to recruit psychiatric nurses in South Africa only elicited a $27 \%$ response rate (Levert, Lucas \& Ortlepp, 2000). The same strategy elicited a response rate of $92 \%$ after being piloted and applied in a similar study amongst Nigerian nurses (Lasebikan \& Oyetunde, 2012). Similarly, research involving mailed cover letters and questionnaires has previously been successful amongst Canadian and American nurses (Choi et al., 1990; Edwards et al., 2002). However, this strategy elicited a low response rate of $36 \%$ amongst Icelandic nurses despite this also being a developed country (Svavarsdottir \& Hallgrimsdottir, 2007).

These differences provide strong justification for undertaking research on improving participation rates amongst nurses in different settings and countries, in order to ensure appropriate development of more specific evidence-based strategies for improving nursing practice (Fineout-Overholt et al., 2004). Within the South African context, nursing practice is particularly challenging as a result of prolonged exposure to context-specific stressors such as a lack of adequate resources within hospitals and a high prevalence of acquired immunodeficiency syndrome (AIDS). It is believed that these challenging environments contribute to higher levels of stress and burnout amongst South African nurses compared to nurses working in other parts of the world (Levert et al., 2000). However, given the limited number of studies amongst nurses within developing contexts, especially the South African context, such challenges are not well understood (Khamisa, Peltzer \& Oldenburg, 2013). In order to fill these gaps in knowledge, nurse participation in research is necessary. Within the South African context, no study assessing the feasibility of previously successful recruitment strategies for the improvement of nurse participation in research could be found. Therefore, in order to improve nursing practice by better understanding specific challenges such as higher levels of stress and burnout (Levert et al., 2000), such novel insight on improving response rates is necessary.

\section{Objectives}

The primary aim of this study was to evaluate the impact of three different recruitment methods for increasing participation rates of South African nurses in a study about the contributing factors and outcomes of work-related burnout within the nursing environment.

It was hypothesised that:

- Information dissemination by the shift manager about the importance of the study will result in higher response rates amongst nurses.

- Involvement of the shift managers in questionnaire distribution will elicit higher response rates.

- Issuing reminders to participants to complete and return questionnaires will improve response rates.

\section{Research design Research approach}

A quantitative cross-sectional survey was conducted to evaluate three recruitment methods for their impact on recruitment and participation rates amongst South African nurses working at a private hospital in Johannesburg. Primary data was used and analysed using descriptive as well as inferential statistical methods. 


\section{Research method}

\section{Research participants}

Following ethical approval from the Monash University Human Research Ethics Committee, permission was given by the selected hospital in South Africa. Two hundred and fifty nurses between the ages of 20 and 70 years, working at a private hospital in Johannesburg, South Africa, were randomly selected from the payroll and invited to participate in this study. This method of selection ensured that all nurses at the chosen hospital had an equal chance of being selected. This reduced bias and enhanced representativeness. Of the 250 selected nurses, 201 agreed to participate in the study. Willing participants were randomly divided into three groups, resulting in 67 nurses being assigned to each group. Each group was recruited using a different method. Group 1 received verbal information and questionnaires from the researcher, group 2 received written information and questionnaires from the researcher and group 3 received verbal information and questionnaires from the shift manager.

Table 1 shows the socio-demographic characteristics of participants, who consisted of mostly black female registered nurses between the ages of 31 and 40, with two to five years working experience. Demographic differences were evident: auxiliary nurses showed a higher response rate to recruitment by the researcher, whereas registered nurses responded more favourably to recruitment by their shift manager. This difference was significant $(p=0.451)$.

\section{Measuring instruments}

All participants in the various groups received a consent form and five questionnaires consisting of a socio-demographic questionnaire, nursing stress indicator (NSI), Maslach burnout inventory - human services survey (MBI-HSS), job satisfaction survey (JSS) and general health questionnaire (GHQ).

Socio-demographic questionnaire: The socio-demographic questionnaire consisted of questions pertaining to the age, gender, level of education, level of experience, population group and number of days or hours worked per week.

NSI: The NSI, developed by Rothmann, Van der Colff and Rothmann (2006), specifically measures the frequency and severity of work-related stress amongst nurses; it has been validated amongst South African nurses and consists of 124 items. The first 62 statements are rated in terms of perceived intensity of the particular stressor on a nine-point scale, ranging from 1 (low) to 9 (high). In the second part of the questionnaire, participants rate the statements on a 10-point scale ranging from 0 (no days) to $9+$ (more than 9 days) in terms of the frequency with which they experienced the stressors over a period of six months.

MBI-HSS: The MBI-HSS has been specifically designed to measure burnout amongst individuals working in the human services and health care occupations such as nursing. With 22 items in the form of statements based on personal feelings and attitudes, the emotional exhaustion (EE) subscale

TABLE 1: Socio-demographic characteristics by recruitment strategy used.

\begin{tabular}{|c|c|c|c|c|c|c|c|c|}
\hline \multirow[t]{3}{*}{ Variable } & \multicolumn{8}{|c|}{ Response recruitment strategy } \\
\hline & \multicolumn{2}{|c|}{ Group $1(n=52)$} & \multicolumn{2}{|c|}{ Group $2(n=46)$} & \multicolumn{2}{|c|}{ Group $3(n=64)$} & \multicolumn{2}{|c|}{ Total $(n=162)$} \\
\hline & $n$ & $\%$ & $n$ & $\%$ & $n$ & $\%$ & $n$ & $\%$ \\
\hline \multicolumn{9}{|l|}{ Age } \\
\hline $21-30$ years & 15 & 28.8 & 15 & 32.6 & 17 & 26.6 & 46 & 28.6 \\
\hline $31-40$ years & 18 & 34.6 & 15 & 32.6 & 20 & 31.2 & 52 & 32.1 \\
\hline $41-50$ years & 12 & 23.1 & 10 & 21.7 & 14 & 21.9 & 36 & 22.0 \\
\hline More than 50 years & 7 & 13.5 & 6 & 13.0 & 13 & 20.3 & 28 & 17.3 \\
\hline \multicolumn{9}{|l|}{ Gender } \\
\hline Male & 5 & 9.6 & 5 & 10.9 & 3 & 4.7 & 12 & 7.1 \\
\hline Female & 47 & 90.4 & 41 & 89.1 & 61 & 95.3 & 150 & 92.9 \\
\hline \multicolumn{9}{|l|}{ Population group } \\
\hline Black & 44 & 84.6 & 35 & 76.1 & 51 & 79.7 & 129 & 79.5 \\
\hline White & 7 & 13.5 & 8 & 17.4 & 12 & 18.8 & 28 & 17.6 \\
\hline Indian & 1 & 1.9 & 1 & 2.2 & 1 & 1.6 & 3 & 1.8 \\
\hline Mixed-race & 0 & 0.0 & 2 & 4.3 & 0 & 0.0 & 2 & 1.2 \\
\hline \multicolumn{9}{|l|}{ Qualification } \\
\hline Auxiliary nurse & 24 & 46.2 & 16 & 34.8 & 21 & 32.8 & 57 & 35.4 \\
\hline Enrolled nurse & 13 & 25.0 & 14 & 30.4 & 18 & 28.1 & 46 & 28.3 \\
\hline Registered nurse & 15 & 28.8 & 16 & 34.8 & 25 & 39.1 & 59 & 36.3 \\
\hline \multicolumn{9}{|l|}{ Experience } \\
\hline Less than 1 year & 5 & 9.6 & 3 & 6.5 & 10 & 15.6 & 20 & 12.2 \\
\hline $2-5$ years & 17 & 32.7 & 19 & 41.3 & 20 & 31.2 & 55 & 34.2 \\
\hline $6-10$ years & 11 & 21.2 & 6 & 13.0 & 8 & 12.5 & 23 & 14.0 \\
\hline $11-15$ years & 3 & 5.8 & 6 & 13.0 & 5 & 7.8 & 14 & 8.9 \\
\hline $16-20$ years & 8 & 15.4 & 2 & 4.3 & 1 & 1.6 & 7 & 4.5 \\
\hline $21-25$ years & 2 & 3.8 & 1 & 2.2 & 6 & 9.4 & 11 & 6.5 \\
\hline More than 25 years & 6 & 11.5 & 9 & 19.6 & 14 & 21.9 & 32 & 19.6 \\
\hline
\end{tabular}


(nine items) includes statements such as 'I feel emotionally drained from my work', the de-personalisation (DP) subscale (five items) includes statements such as 'I feel I treat some recipients as if they were impersonal objects' and the personal accomplishment (PA) subscale includes statements such as 'I have accomplished many worthwhile things in this job'. This instrument has been found to be a reliable measure of burnout amongst nurses with Cronbach's alpha values reported as 0.90 for EE, 0.71 for DP and 0.79 for PA (Maslach, Jackson \& Leiter, 1996). More recently, alpha values of 0.91 for the EE subscale, 0.62 for the DP subscale and 0.76 for the PA subscale have been reported (Chao, McCallion \& Nickle, 2011).

JSS: The JSS was developed by Spector $(1985,1997)$ and measures employees' job satisfaction within organisations in the social sector. With nine facets (appreciation, communication, co-workers, fringe benefits, job conditions, nature of work itself, organisation itself, the organisation's policies and procedures, pay, personal growth, promotion opportunities, recognition, security and supervision), the questionnaire consists of a set of 36 items. Participants respond in terms of how true a statement is (higher scores indicate 'truer' statements). Participants' responses are based on a rating scale in the form of a six-point Likert-type scale ranging from 1 (disagree very much) to 6 (agree very much). The JSS is a reliable instrument with Cronbach's alpha coefficients exceeding 0.70 for all the scales.

GHQ: The GHQ was developed by Goldberg and Hillier (1979) to detect psychiatric illness as well as current psychological states and perceived quality of life. This questionnaire has several versions based on the original 60-item version (GHQ30, GHQ-28 and GHQ-12). The GHQ-28 with four subscales, somatic symptoms (SS), anxiety and insomnia (AS), social dysfunction (SD) and severe depression (DS), is preferred and was used in this study. Participants indicate how they feel about each item using a four-point Likert-type scale, ranging from 1 (better than usual) to 4 (much worse). A high score on the GHQ signifies poor general health and vice versa. This instrument is reliable with Cronbach's alpha values ranging between 0.69 and 0.90 for all scales (Goldberg \& Hillier, 1979).

\section{Research procedure}

The three randomly selected groups of nurses were recruited using the following strategies:

Group 1: The first group of nurses $(n=67)$ was sent invitation letters inviting them to attend an information session, during which the researcher personally presented information explaining the importance and value of the study as well as the role of participants. Following the presentation, the researcher distributed a consent form and five questionnaires for completion to each participant.

Group 2: The second group of nurses $(n=67)$ received an invitation pack from the researcher containing a written explanatory statement with information about the importance and value of the study as well as the role of participants, a consent form and five questionnaires to be completed.

Group 3: The third group of nurses $(n=67)$ received information about the importance and value of the study as well as the role of participants from their shift managers who then distributed the consent form and five questionnaires to willing participants for completion.

Paper-based questionnaire completion was estimated to take no more than 20-30 minutes and took place over a period of two weeks. All groups were requested to anonymously complete the consent form as well as the questionnaires and to return these by placing them in a sealable envelope that was provided. The sealed envelopes containing completed consent forms and questionnaires were to be put into sealed boxes situated around the hospital; the boxes could only be opened by the researcher, thus ensuring privacy and confidentiality. Reminders were issued two weeks after initial questionnaire distribution by word of mouth during meetings and in writing by posters placed on noticeboards around the hospital.

\section{Statistical analysis}

This study used a cross-sectional study design. Descriptive analysis as well as odds ratios (with 95\% confidence intervals) were used to analyse the data. Participant responses were entered into SPSS (version 20) and analysed using frequencies and percentages. Response rates and questionnaire completion rates were used to compare the three recruitment strategies for this study concerning workrelated stress, burnout, job satisfaction and general health of South African nurses.

\section{Results}

Of a total 250 invited nurses, 201 agreed to participate in the study (80.4\%), with 162 returning the questionnaires (81\%). Of the 162 participants who returned questionnaires, 143 completed all the questionnaires (88.3\%), and $19(11.7 \%)$ did not. Sixteen of the 19 incomplete questionnaires were incomplete for the NSI (84.2\%). Three participants did not complete any of the questionnaires. Therefore, the majority of the incomplete questionnaires were partially incomplete $(n=16)$ and the minority were fully incomplete $(n=3)$.

Concerning the first hypothesis, the recruitment strategy involving information dissemination by the shift manager elicited a higher response rate (39.5\%) than to recruitment strategies in which information was disseminated verbally (32.1\%) and in written form (28.4\%) by the researcher. In terms of the second hypothesis, distribution of questionnaires by shift managers also elicited the highest response rate (39.5\%) compared to recruitment strategies involving questionnaire distribution by the researcher (32.1\% and $28.4 \%$ ). For the third hypothesis, reminders boosted response rates by $10 \%$. Before reminders were issued 142 (71\%) participants had returned the questionnaires. 
TABLE 2: Effectiveness of recruitment strategies.

\begin{tabular}{ll}
\hline Groups & Odds ratio (95\% confidence interval) \\
\hline Group 1 vs Group 2 & $1.58(0.73,1.17)$ \\
Group 3 vs Group 1 & $6.15(1.69,22.4)$ \\
Group 3 vs Group 2 & $9.74(2.74,34.6)$ \\
\hline
\end{tabular}

Table 2 illustrates the relative effectiveness of the three recruitment strategies. Information dissemination and questionnaire distribution by the shift managers (Group 3) was the most effective recruitment strategy. There was no difference in response rates achieved using the other two recruitment methods (Group 1 vs Group 2).

\section{Discussion}

This study was aimed at testing the feasibility of three recruitment methods and measurement tools amongst nurses within the South African context. An overall response rate of $81 \%$ was achieved in this study.

According to hypothesis one and hypothesis two, information dissemination and questionnaire distribution by shift managers was expected to result in higher response rates amongst nurses. This was supported by the findings, which showed that the highest response rate $(39.5 \%)$ was elicited from the third group of nurses who received information and questionnaires from their shift managers. It was also found that the odds were greater for receiving higher response rates when the nurses received information and questionnaires from their shift managers versus the researcher.

These findings support previous research demonstrating that overcoming organisational barriers by involving the nurse unit and shift managers in nursing research increases response rates (Bolton et al., 2005; Choi et al., 1990). This strategy applied in developing countries has also been successful in recruiting nurses to participate in research. Van der Doef et al. (2012) obtained response rates of $74.9 \%$ amongst Tanzanian nurses, $76.4 \%$ amongst Kenyan nurses and $70.7 \%$ amongst Ugandan nurses through the assistance of matrons in the questionnaire distribution process.

The success of this strategy has been attributed to the nurses' familiarity with their superiors whom they trust and respect (Altuntas \& Baykal, 2010; Broyles et al., 2011). Due to the perception of nurses that their superiors are credible individuals, they feel confident to overcome negative beliefs and concerns they usually experience with regard to unfamiliar individuals, which encourages an interest in participation (Hummers-Pradier et al., 2008; Weierbach et al., 2010). This is substantiated by the findings of this study, which showed that involving the researcher (unfamiliar to the nurses) in the recruitment process elicited a lower response rate of $32.1 \%$.

It was also hypothesised that issuing reminders to participants to complete and return questionnaires would improve response rates. This can be explained by the time-consuming and complex nature of nursing tasks, which may act as a barrier to research participation. Hence, issuing reminders prompts nurses to complete and return questionnaires (Corcoran, 2007; Cummins, 2006; Weierbech et al., 2010). This hypothesis was supported in that issuing reminders to participants to complete and return questionnaires improved response rates by $10 \%$. Previous studies have reported similar findings arguing that issuing reminders to complete and return questionnaires improves response rates by up to 10\% (Shih \& Fan, 2008). Reminders are therefore successful in obtaining high response rates as reported in a number of studies eliciting over $70 \%$ response rates (Becker, Cookston \& Kuberg, 2000; Bolton et al., 2005; Guise, Chambers, Valimaki \& Makkonen, 2010).

Additional recruitment strategies, such as written information in the form of a detailed cover letter explaining the study, have been found to be successful in previous studies both in developing (Lasebikan \& Oyetunde, 2012) and developed (Hill et al., 2006) countries. However, the current study found that this strategy elicited the lowest response rate $(28.4 \%)$. In line with these findings, research has confirmed that lack of face-to-face and interpersonal recruitment strategies jeopardise high response rates (Broyles et al., 2011). Studies that have used face-to-face recruitment strategies have elicited high response rates of up to $100 \%$ (Thorsen et al., 2011). This result is due to the fact that it allows for engagement with nurses by directly addressing any misconceptions about the study, thereby increasing their interest in participation (Broyles et al., 2011).

In terms of the feasibility of the measurement tools used in this study, a high non-completion rate was found for the NSI (84.2\%) which consisted of 124 items. Previous studies have also reported higher non-completion rates for lengthy questionnaires confirming that shorter questionnaires yield better completion and response rates (Asch, Jedrziewski \& Christakis, 1997; Edwards et al., 2002; Edwards et al., 2009; Thran \& Hixon, 2000). Increased odds of response to shorter questionnaires have been reported as a result of them being less time consuming and requiring less effort (Jepson, Asch, Hershey \& Ubel, 2005).

Of the three recruitment strategies applied in this study, the most successful was the one that involved information dissemination and questionnaire distribution by the shift manager, with a high overall response rate of $81 \%$ after the issuing of reminders. Differences in response rates between the group of nurses receiving questionnaires from their shift managers and those receiving questionnaires from the researcher explain the importance and benefit of using a familiar person in recruiting nurses for research.

\section{Limitations, implications and future direction}

Although these findings should be interpreted with caution owing to the small sample of nurses recruited from one 
private hospital, the current study identifies successful strategies in recruiting South African nurses for research. As such, involving nursing management in the recruitment and data collection process produces more favourable response rates; reminders are successful in boosting response rates and the use of shorter questionnaires improves response rates. Further testing of recruitment strategies and measurement tools amongst South African nurses in other private hospitals as well as in the public sector is important in validating the findings of this study and discovering other ways to improve response rates.

\section{Conclusion}

Recruitment challenges are not well understood amongst nurses, which explains the lower research participation rates amongst this population versus other populations. This study identifies some successful recruitment strategies specifically for increasing the participation of South African nurses in research. Further research aimed at understanding recruitment challenges in this context will contribute to higher participation rates amongst nurses, thus enabling the development of evidence-based strategies for improving nursing practice in developing countries such as South Africa.

\section{Acknowledgements Competing interests}

The authors declare that they have no financial or personal relationships that may have inappropriately influenced them in writing this article.

\section{Authors' contributions}

N.K. (Monash South Africa and Monash University) was the project leader. K.P. (University of Limpopo, University of the Free State and Mahidol University) provided continued guidance throughout every step of the project and was involved with conceptualisation of the manuscript as well as data analysis. D.I. (Monash University) assisted with data analysis and interpretation of results. B.O. (Monash University) was responsible for overseeing the project planning and implementation, whilst being involved with the funding application and ethics approval for the project.

\section{References}

Altuntas, S., \& Baykal, U. (2010). Relationship between nurses' organisational trust levels and their organisational citizenship behaviors. Journal of Nursing Scholarship, 42, 186-194. http://dx.doi.org/10.1111/j.1547-5069.2010.01347.x

Asch, D.A., Jedrziewski, M.K., \& Christakis, N.A. (1997). Response rates to mail surveys published in medical journals. Journal of Clinical Epidemiology, 50, 1129-1136. http://dx.doi.org/10.1016/S0895-4356(97)00126-1

Becker, H., Cookston, J., \& Kuberg, V. (2000). Issues in clinical nursing research Mailed survey followups: Are postcard reminders more cost-effective than second questionnaires? WesternJournal of Nursing Research, 22, 642-647. http://dx.doi. org/10.1177/01939450022044647

Bolton, L.B., Shihady, I.R., Bennett, C., Broussard, P., Fridman, M., Fink, A., et al. (2005). Engaging nurse leaders in health services research. Journal of Nursing Administration, 35, 238-243. http://dx.doi.org/10.1097/00005110-20050500000007
Broyles, L.M., Rodriguez, K.L., Price, P.A, Bayliss, N.K., \& Sevick, M.A. (2011) Overcomingbarriers to the recruitment of nurses as participants in health care research. Qualitative Health Research, 21, 1705-1718. http://dx.doi. care research. Qualitative Health
org/10.1177/1049732311417727

Burns, N., \& Grove, S.K. (2007). Understanding nursing research: Building an evidencebased practice. (4th. edn.). St Louis: Saunders Elsevier.

Chan, G.K., Barnason, S., Dakin, C.L., Gillespie, G., Kamienski, M.C., \& Stapleton, S. (2011).Barriers and perceived needs for understanding and using research among emergency nurses. Journal of Emergency Nursing, 37, 24-31. http://dx.doi. org/10.1016/j.jen.2009.11.016

Chao, S.F., McCallion, P., \& Nickle, T. (2011). Factorial validity and consistency of the Maslach Burnout Inventory among staff working with persons with intellectual disability and dementia. Journal of Intellectual Disability Research, 55, 529-536. http://dx.doi.org/10.1111/j.1365-2788.2011.01413.x

Choi, B.C.K., Pak, A.W.P., \& Purdham, J.T. (1990). Effects of mailing strategies on responserate, response time, and cost in a questionnaire study among nurses. Epidemiology, 1, 72-74. http://dx.doi.org/10.1097/00001648-199001000-00015

Cook, J.V., Dickinson, H.O., \& Eccles, M.P. (2009). Response rates in postal surveys of healthcare professionals between 1996 and 2005: An observational study. BMC Health Services Research, 9, 160. http://dx.doi.org/10.1186/1472-6963-9-160

Corcoran, S.A. (2007). Task complexity and nursing expertise as factors in decision makingprocesses used by nurses to plan patient care. Nursing Research, 35, 107-112.

Cummins, H.J. (2006, December). Nurses cope with increasing job pressures. Minneapolis StarTribune. Retrieved September 26, 2013, from http://mnnurses. $\mathrm{org} / \mathrm{sites} /$ default/files/documents/Complexity\%20compression\%2012-18-06.pdf

Edwards, P.J., Roberts, I.G., Clarke, M.J., DiGuiseppi, C., Pratap, S., Wentz, R., et al. (2002). Increasing response rates to postal questionnaires: Systematic review. British Medical Journal, 324, 1183. http://dx.doi.org/10.1136/bmj.324.7347.1183

Edwards, P.J., Roberts, I.G., Clarke, M.J., DiGuiseppi, C., Wentz, R., Kwan, I., et al. (2009). Methods to increase response to postal and electronic questionnaires. Cochrane Database of Systematic Reviews, 3, Art. No. MR000008. http://dx.doi. org/10.1002/14651858.MR000008.pub4

Fineout-Overholt, E., Levin, R.G., \& Melnyk, B.M. (2004). Strategies for advancing evidence based practice in clinical settings. Journal of the New York State Nurses Association, 35, 28-32.

Goldberg, D.P., \& Hillier, V.F. (1979). A scaled version of the General Health Questionnaire. Psychological Medicine, 9, 139-145. http://dx.doi.org/10.1017/ S0033291700021644

Gore-Felton, C., Koopman, C., Bridges, E., Thoresen, C., \& Spiegel, D. (2002). An example of maximizing survey return rates: Methodological issues for health professionals. Evaluation and the Health Professions, 25, 152-168. http://dx.doi. org/10.1177/01678702025002002

Guise, V., Chambers, M., Valimaki, M., \& Makkonen, P. (2010). A mixed-mode approach to data collection: Combining web and paper questionnaires to examine nurses attitudes to mental illness. Journal of Advanced Nursing, 66, 1623-1632. http:// dx.doi.org/10.1111/j.1365-2648.2010.05357.x

Hill, C.A., Fahrney, K., Wheeless, S.C., \& Carson, C.P. (2006). Survey response inducements for registered nurses. Western Journal of Nursing Research, 28, 322-334. http://dx.doi.org/10.1177/0193945905284723

Hummers-Pradier, E., Scheidt-Nave, C., Martin, H., Heinemann, S., Kochen, M.M., \& Himmel, W. (2008). Simply no time? Barriers to GPs' participation in primary health care research. Family Practice, 25, 105-112. http://dx.doi.org/10.1093/ fampra/cmn015

Jacobson, A.F., Warner, A.M., Fleming, E., \& Schmidt, B. (2008). Factors influencing nurses' participation in clinical research. Gastroenterology Nursing, 31, 198-208. http://dx.doi.org/10.1097/01.SGA.0000324112.63532.a2

Jepson, C., Asch, D.A., Hershey, J.C., \& Ubel, P.A. (2005). In a mailed physician survey,questionnaire length had a threshold effect on response rate. survey, questionnaire length had a threshold effect on response rate.
Journal of Clinical Epidemiology, 58, 103-105. http://dx.doi.org/10.1016/j. Journal of Clinical
jclinepi.2004.06.004

Khamisa, N., Peltzer, K., \& Oldenburg, B. (2013). Burnout in relation to specific contributing factors and health outcomes among nurses: A systematic review. International Journal of Environmental Research and Public Health, 10, 2214International Journal of Environmental Research
2240. http://dx.doi.org/10.3390/ijerph10062214

Lasebikan, V.O., \& Oyetunde, M.O. (2012). Burnout among nurses in a Nigerian general hospital: Prevalence and associated factors. ISRN Nursing, 2012, 1-6. http://dx.doi.org/10.5402/2012/402157

Levert, T., Lucas, M., \& Ortlepp, K. (2000). Burnout in psychiatric nurses: Contributions of the work environment and a sense of coherence. South African Journal of Psychology, 30, 36-41. http://dx.doi.org/10.1177/008124630003000205

Madu, S.N., \& Mamomane, J. (2003). Stress among nurses in rural hospitals in South Africa. Journal of Social Sciences, 7, 209-213.

Maslach, C., Jackson, S.E., \& Leiter, M.P. (1996). Maslach Burnout Inventory Manual. (3rd edn.). California: Consulting Psychologists Press.

Purkis, J., Jackson, J.A., Hundt, G., \& Stockman, C. (2008). Increasing nursing research capacity in the workplace. Nursing Times, 104, 28-31.

Rothmann, S., Van Der Colff, J.J., \& Rothmann, J.C. (2006). Occupational stress of nurses in South Africa. Curationis, 29, 24-25. http://dx.doi.org/10.4102/ curationis.v29i2.1069

Shih, T. \& Fan, X. (2008). Comparing response rates from web and mail surveys: A meta analysis. Field Methods, 20, 249-271. http://dx.doi.org/10.1177/1525822X08317085 
Spector, P.E. (1985). Measurement of human service staff satisfaction: Development of the job satisfaction survey. American Journal of Community Psychology, 13, 693-713.

Spector, P.E. (1997). Job satisfaction: Application, assessment, causes and consequences. London: Sage Publications.

Svavarsdottir, M.H., \& Hallgrimsdottir, G. (2007). Participation of Icelandic nurses in smoking cessation counseling. Journal of Clinical Nursing, 17, 1335-1341. http:// dx.doi.org/10.1111/j.1365-2702.2006.01874.x

Thorsen, V.C., Tharp, A.L., \& Meguid, T. (2011). High rate of burnout among materna health staff at a referral hospital in Malawi: A cross sectional study. BMC Nursing, 10(9), 1-7.

Thran, S.L., \& Hixon, J.S. (2000). Physician surveys: Recent difficulties and proposed solutions. Proceedings of the American Statistical Association. Retrieved December 10, 2012, from http://www.amstat.org/sections/SRMS/Proceedings/ papers/2000_035.pdf
Ulrich, C.M., \& Grady, C. (2004). Financial incentives and response rates in nursing research. Nursing Research, 53, 73-74. http://dx.doi.org/10.1097/00006199200403000-00001

Van der Doef, M. Mbazzi, F. B., \& Verhoeven, C. (2012). Job conditions, job satisfaction somatic complaint and burnout among East African nurses. Journal of Clinical Nursing, 21, 1763-1775. http://dx.doi.org/10.1111/j.1365-2702.2011.03995.x

Webb, B. (2002). Using focus groups as a research method: A personal experience. Journal of Nursing Management, 10, 27-35. http://dx.doi.org/10.1046/j.09660429.2001.00273.x

Weierbech, F.M., Glick, D.F., Fletcher, K., Rowlands, A., \& Lyder, C.H. (2010). Nursing research and participant recruitment: Organisational challenges and strategies. Journal of Nursing Administration, 40, 43-48. http://dx.doi.org/10.1097/ NNA.0b013e3181c97afb 